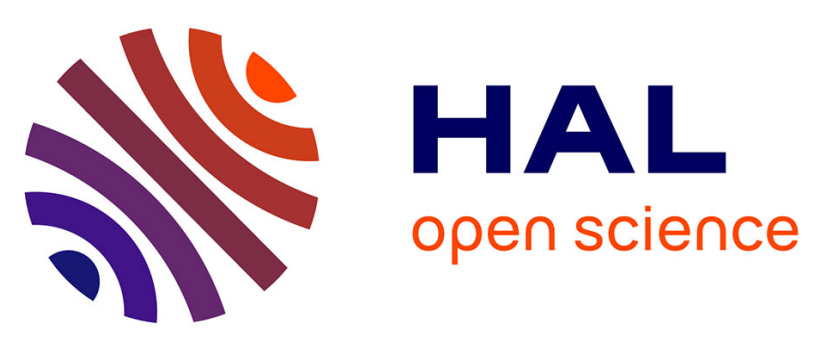

\title{
Monitoring biological rhythms through the dynamic model identification of an oyster population
}

Hafiz Ahmed, Rosane Ushirobira, Denis Efimov, Damien Tran, Mohamedou Sow, Pierre Ciret, Jean-Charles Massabuau

\section{- To cite this version:}

Hafiz Ahmed, Rosane Ushirobira, Denis Efimov, Damien Tran, Mohamedou Sow, et al.. Monitoring biological rhythms through the dynamic model identification of an oyster population. IEEE transactions on systems, man, and cybernetics, 2017, 47 (6), 10.1109/TSMC.2016.2523923 . hal-01220311

\section{HAL Id: hal-01220311 \\ https://hal.inria.fr/hal-01220311}

Submitted on 26 Oct 2015

HAL is a multi-disciplinary open access archive for the deposit and dissemination of scientific research documents, whether they are published or not. The documents may come from teaching and research institutions in France or abroad, or from public or private research centers.
L'archive ouverte pluridisciplinaire HAL, est destinée au dépôt et à la diffusion de documents scientifiques de niveau recherche, publiés ou non, émanant des établissements d'enseignement et de recherche français ou étrangers, des laboratoires publics ou privés. 


\title{
Monitoring biological rhythms through the dynamic model identification of an oyster population
}

\author{
Hafiz Ahmed, Rosane Ushirobira, Denis Efimov, Damien Tran, Mohamedou Sow, Pierre Ciret, Jean-Charles \\ Massabuau
}

\begin{abstract}
The measurements of valve activity in a population of bivalves under natural environmental conditions (16 oysters in the Bay of Arcachon, France) are used for a physiological model identification. A nonlinear auto-regressive exogenous (NARX) model is designed and tested. The method to design the model has two parts. 1) Structure of the model: The model takes into account the influence of environmental conditions using measurements of the sunlight intensity, the moonlight, tide levels, precipitation and water salinity levels. A possible influence of the internal circadian/circatidal clocks is also analyzed. 2) Least square calculation of the model parameters. Through this study, it is demonstrated that the developed dynamical model of the oyster valve movement can be used for estimating normal physiological rhythms of permanently immersed oysters and can be considered for detecting perturbations of these rhythms due to changes in the water quality, i.e. for ecological monitoring.
\end{abstract}

Index Terms-Dynamic Model, Ecological Monitoring, Oyster Population, System Identification, Circadian Rhythm Modeling, Bioindicator.

\section{INTRODUCTION}

Since last century, the quality of our world's environment is changing swiftly causing significant changes in the marine water quality. For this reason, nowadays, local, regional and international legislation has strict laws and recommendations on the protection of aquatic environment against the disposal of harmful and dangerous substances ${ }^{1}$. In order to abide by these laws and recommendations for the protection of aquatic environment, a large scale monitoring of water quality is essential [1]. However, the realization of such an extensive network of aquatic monitoring is very costly and technically challenging from an engineering point of view. Researchers and engineers are then

Hafiz Ahmed, Rosane Ushirobira and Denis Efimov are with the NonA team at Inria, Parc Scientifique de la Haute Borne, 40 avenue Halley, 59650 Villeneuve d'Ascq, France, \{hafiz.ahmed, rosane.ushirobira, denis.efimov@inria.fr\}. Damien Tran, Mohamedou Sow, Pierre Ciret and JeanCharles Massabuau are with Université Bordeaux 1, Centre National de la Recherche Scientifique (CNRS), Unité Mixte de Recherche (UMR) 5805 Environnement et Paléoenvironnement Océanique et Continental (EPOC), Arcachon, France and the EA team at UMR 5805 EPOC-OASU, Bordeaux, France, \{d.tran, m.sowm p.ciret, jc.massabuau@epoc.u-bordeaux1.fr \}. Denis Efimov is also with CRIStAL UMR 9189, Ecole Centrale de Lille, Avenue Paul Langevin, 59651 Villeneuve d'Ascq, France and with the Department of Control Systems and Informatics, Saint Petersburg State University of Information Technologies Mechanics and Optics (ITMO), Kronverkskiy av. 49, Saint Petersburg, 197101, Russia.

Hafiz Ahmed is partially supported by the regional council of Nord Pas de Calais, France. This work was partially supported by the Government of Russian Federation (Grant 074-U01) and the Ministry of Education and Science of Russian Federation (Project 14.Z50.31.0031).

${ }^{1}$ http://europa.eu/legislationsummaries/environment/ waterprotectionmanagement/128017aen.htm;

http://water.epa.gov/scitech/swguidance/standards/criteria/aqlife/index.cfm; http://frdc.com.au/environment/aquaticenvironment/Pages/default.aspx. working on an indirect monitoring of the aquatic environment from behavioral and physiological responses of representatives of the marine fauna [2], [3], [4], [5], [6], [7]. Bio-indicators demonstrate high efficiency, for instance through bio-accumulation of contaminants/pollutants in their tissues ${ }^{2}$. Nevertheless, until now, large scale extensive aquatic monitoring does not seem viable and realistic as it involves intensive exploitation of human resources for the collection of samples, complex chemical analysis and so on [8]. A solution of the aforementioned problem is to develop unmanned autonomous systems using biosensors, able to work round the clock, at high frequency by remote control. As of today, networks of such online sensors, operating at large scale do not exist and are still a matter of research. To fulfill the objective just mentioned before, an installation of numerous online remote sensors is required, working at high frequency for instant collection of information on a daily basis in marine environment [9]. Behavioral and physiological responses of wildlife to contamination are very sensitive and these responses can be used for an indirect monitoring of the aquatic environment [10]. However, a limiting factor today is that it requires high volumes of data, whose analysis needs appropriate mathematical analysis, running near real-time [11]. Other difficulties lie in the fact that animals may be heavily influenced by surrounding environment, group interactions and internal rhythms (e.g. feeding, breathing, spawning) [12].

Observation of the opening and closing activities of bivalves is a possible way to evaluate their physiological behavior in reaction to their nearby water. The deviations from a considered normal behavior can be used for detection of a contaminant in surrounding water. Thus, our aim was to gain more insights into these reference natural conditions by focusing on biological rhythms of their valve activity in situ. The pioneer work that analyzes bivalve's activities through the record of their valve movements (e.g., valvometry) was realized by Marceau [13] with smoked glazed paper. Today, valvometers are commercially available ${ }^{3}$ and are mainly based on the principle of electromagnetic induction, like the Mossel Monitor [14] or the Dreissena Monitor [15], [16]. In recent years, the interest for modeling and estimation of behavior of marine animals directly in real marine conditions has intensively increased [17], [18], [19].

A distinctive and remarkable monitoring solution has been realized in the EPOC CNRS UMR laboratory in Arcachon, France [20], [21], [22], where a new framework for noninvasive valvometry has been developed and implemented successfully since 2006.

\footnotetext{
${ }^{2}$ For example, see the US Mussel Watch, http://ccma.nos.noaa.gov/about/ coast/nsandt/musselwatch.aspx.

${ }^{3}$ http://www.mosselmonitor.nl/
} 


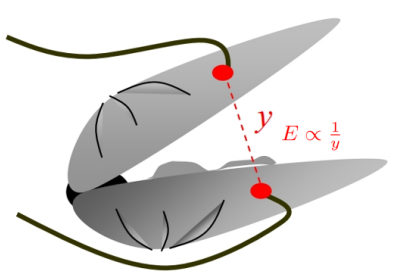

Figure 1. Graphical representation of the distance being estimated by the electrodes

The system can work under field condition for long period of time without in situ human intervention ( $>1-2$ years). No other system according to the best knowledge of the authors has operated for several years like this one even in the laboratory environment. The monitoring solution was tested in the laboratory environment several years before deploying it into the sea. The designed method is strongly based on bivalve's respiratory physiology and ethology. The developed platform for valvometry was built using lightweight electrodes (approximately $100 \mathrm{mg}$ each) linked by thin flexible wires to high-performance electronic units. The electrodes are capable to estimate the distance of opening of shell (see Fig. 1) for a mollusc with an accuracy of a few $\mu \mathrm{m}$. Moreover, in the field, the energy consumption is very low, only 1 watt. One data point is generated every $0.1 \mathrm{sec}$ ( 24 hours per day), for a bivalve, the electronic unit supports connection with 16 animals. Next, the results of measurements are transmitted by a wireless connection to the laboratory, the obtained data is publicly available online on the site of the project ${ }^{4}$. This system allows the bivalves to be studied in their natural environment with minimal experimental constraints. The obtained arrays of data of opening and closing activities of bivalves were used for analysis from different points of view using statistical approaches (estimation of probability density functions for time and amplitude of opening) [20], [21], [22].

Many researchers have studied the behavior of bivalves using valvometry and also through chemical analysis of the tissues of oysters. In [23], [24], authors have studied the impact of persistent organic pollutants on juvenile oysters through chemical analysis. They have shown that active biomonitoring is possible with juvenile oysters. In [25], authors have studied the tissues of oysters collected from various locations of southern Texas. They have concluded through chemical analysis that toxicity in the tissue can be used as an indicator for disturbed environment. Similar approach of using oysters as a biomonitoring tool through chemical analysis can also be found in [26]. However, chemical analysis is essential in all these cases.

In [27], authors have studied the valve activity behavior of two unionid mussel species in a eutrophic lake in southern Finland. Long term fluctuations in valve movements were observed and authors suggested that this fluctuations may be the reflection of the enrichment of pollutants in the mussels. In [28], Asiatic clams were exposed to waters receiving chlorine containing industrial discharges. It was shown that valves of the clams exposed to pollutants opened more often and for longer period than clams not exposed to pollutants. Comparison of valve movement activity

${ }^{4}$ http://molluscan-eye.epoc.u-bordeaux1.fr/ of fresh water mussel between lake and river was done in [29]. It was shown that variability in valve opening is much higher in river than lake. So, it can be concluded from this whole dataset that valve opening activity may have a relation with the habitat of the bivalves.

Recently, the effect of a specific pollutant (i.e. Arsenic) on the valve opening activity in fresh water clam in laboratory environment was done in [30], [31]. In this paper, authors have used statistical modeling approach (hill based dose response model [32]) to see the effect of Arsenic on the valve opening activity by exposing the freshwater clams Corbicula fluminea to Arsenic contaminated water. In [27], it was shown that valve opening behavior is significantly different in their natural habitat than laboratory environment. This limits the scope of the results obtained in [30]. We propose here to develop an indirect monitoring system which is pollutants independent and also deals with natural habitat (i.e. the sea) through rhythmicity identification of an oyster population.

For that purpose, the goal of the present study is the identification of a physiological dynamical model of nonlinear autoregressive exogenous (NARX) type for bivalves using a high volume of data (12.63 Gigabytes). The data came from a population of 16 oysters living in the Bay of Arcachon, France. The model takes into account the influence of external forces (like the sunlight and the moonlight, the tide level, precipitation, water salinity level). Since the behavior of oysters is also guided by internal circadian/circatidal rhythms, their influence is also incorporated in the developed NARX model. The type and the origin of internal circadian/circatidal rhythms of bivalves is rather uncertain, that is why a side result of the present study consists in verifying different hypotheses for modeling of circadian/circatidal rhythms for oysters. The proposed model is of Grey-box type [33].

The outline of the paper is as follows. A brief description of the measurement scheme and experiments is given in Section 2 (a more detailed information can be found in [20], [21], [22]). The model identification procedure is presented in Section 3. The verification of the model and its utility for an ecological monitoring of water quality are discussed in Section 4.

\section{Measurement System Description}

The monitoring site is situated in the Bay of Arcachon, France, at the Eyrac pier (Latitude: $44^{\circ} 40 \mathrm{~N}$, Longitude: $1^{\circ} 10 \mathrm{~W}$ ). The map of the location can be seen in Fig. 2. Sixteen Pacific oysters, Crassostrea gigas, measuring from $8 \mathrm{~cm}$ to $10 \mathrm{~cm}$ in length were permanently installed on this site. These oysters were all from the same age group ( 1.5 years old) and came from the same local supplier. They also all grew in the Bay of Arcachon. They were submerged on the sea bottom (at $3 \mathrm{~m}$ to $7 \mathrm{~m}$ deep in the water, depending on the tide activity).

The principle of the total measurement process including electronic equipment has been first described in [20]. The measurement system was further modified (adjusted to severe open ocean conditions and mainly mechanical not electronic) later on in [34], [35]. A significant advantage of the developed monitoring system (slave unit in the field) is that it is completely autonomous without in situ human interference for one full year. Each animal is equipped with two lightweight coils (sensors), $\approx 100 \mathrm{mg}$ each, attached on the edge of each valve. These coils measure 


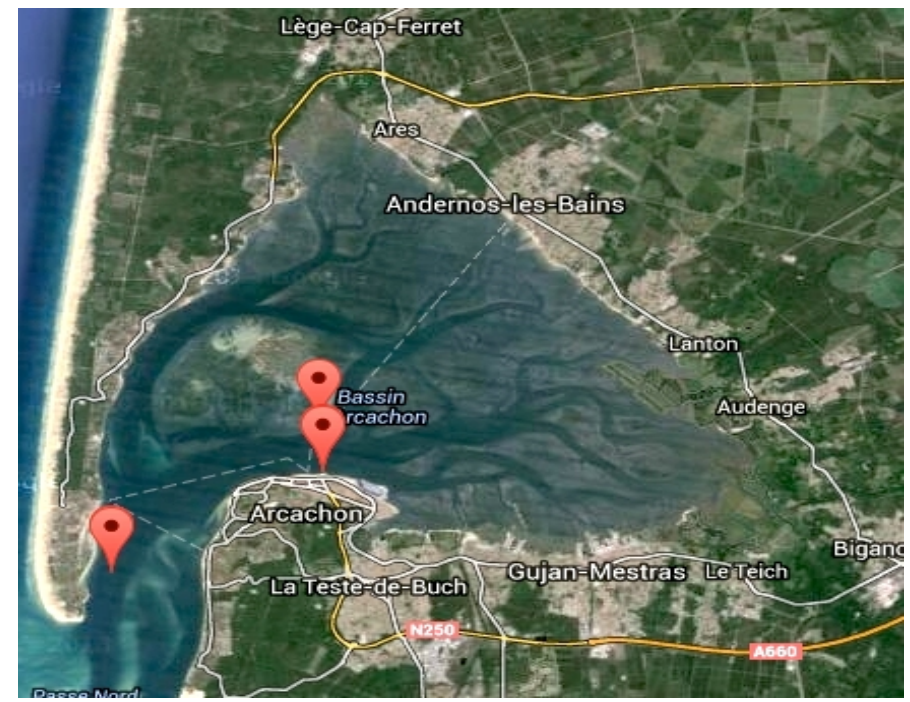

Figure 2. Location map (Courtesy of Google Maps), see also http:// molluscan-eye.epoc.u-bordeaux 1.fr/

$2.5 \times 2.5 \times 2 \mathrm{~mm}$ and were coated with a resin sealing before attaching them on the valves. One of the coils sends a highfrequency sinusoidal signal, that is received by another coil. Measurements are performed every $0.1 \mathrm{sec}$ successively (with the frequency $10 \mathrm{~Hz}$ ) for each of the sixteen animals. This means that the behavior of a particular oyster is measured every $1.6 \mathrm{sec}$. Every day, 54000 triplets (1 distance, 1 stamped time value, 1 animal number) are collected for each oyster. The strength of the electric field produced between the two coils can be written as [21]:

$$
E \propto \frac{1}{y}
$$

where $E$ is the strength of the electric field and $y$ is distance between the point of measurement and the center of the transmitting coil. Equation (1) leads to estimation of the distance between coils. The measured signal ( $D_{m v}$ in millivolts) is converted into distance in millimeters $\left(D_{m m}\right)$ using the following calibration model [21]

$$
\hat{D}_{m v}=\frac{151}{\left(\hat{D}_{m m}\right)^{0.35}}-1.48
$$

The distance being estimated can be seen in Fig. 1.

On the shore, a second electronic unit takes care the data acquisition and transmission. This unit is equipped with a GSM/GPRS modem and uses Linux operating system for driving the first control unit submerged in the water, managing the data storage with a time stamp, accessing the Internet, and transferring the data. An original self-developed software module runs on mobile phone technology. At the end of a working day, the collected data is transmitted to a central workstation server (the master unit) located in the Marine Station at Arcachon, France. The valve activity data is stored in a central database and the access to this database is provided via an Internet connection (under some restrictions on the amount of data). A schematic description of the monitoring system is presented in Fig. 3.

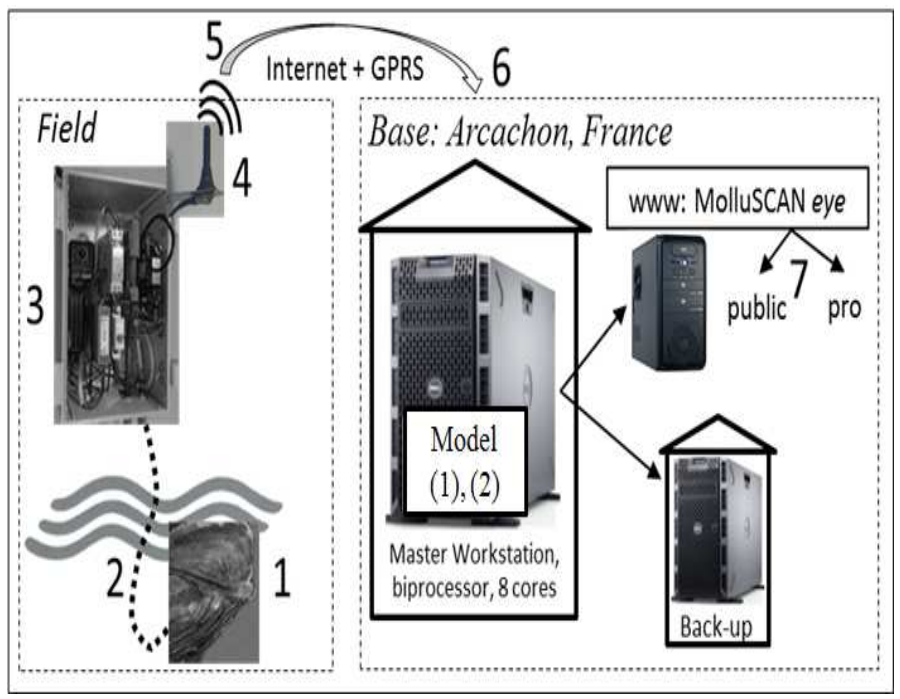

Figure 3. [22] Synoptic representation of the system, from field to laboratory: (1) Oyster equipped with two electrodes and 1st level electronic card in a waterproof case (immersed); (2) electrical connection between the first and the second electronic cards (umbilical); (3) 2nd level electronic card out of water; (4) GPRS antennae (5) GPRS and Internet connection; (6) Marine Station of Arcachon (Master unit) ready for daily update and for feeding internet (Google: molluscan eye); (7) daily update on internet for the general public (restricted access) and professionals (full access).

The collected tidal data includes a measurement of the height of the water column every hour, while the times and levels of low and high tides are provided by the hydrographic and oceanographic service of the marine ${ }^{5}$. To take into account the nycthemeral rhythm of the bivalve, the sun and the moon positions at the sampling site have been used [36], [37].

It is worth to note that data losses in transmission were sometimes observed due to impairment of data transfer.

\section{Model IDENTIFICATION}

Summarizing the description given in the previous section, after a specified duration of the experiment, the electronic system provides a matrix of values of opening of valves for each oyster $P_{i, j}$ for $1 \leq i \leq N, \quad 1 \leq j \leq n, \quad$ where $n=16$ is the number of oysters in the experiment and $N$ is the number of measured points, $N=54000 * N_{\text {days }}$ with $N_{\text {days }}>0$ is the number of days used for the identification of the model. The actual valve distance is given in millimeters $(\mathrm{mm})$ and the range is between 0 to $12 \mathrm{~mm}$. In our case, the data of 2007 collected at the Eyrac pier in Arcachon has been used. So, $N_{\text {days }}=365$. For the population i.e. for 16 oysters, the measurement system gave us total 315.36 million data points. In addition to the valve distance, the values $S_{i}, M_{i}, W_{i}$ are also provided for $1 \leq i \leq N$, they characterize the sun and moon positions with respect to the horizon in degrees and the tide levels in meters respectively. The signals $S_{i}$ and $M_{i}$ take negative values for the corresponding positions below the horizon line. Besides the three periodic signals (i.e. $S_{i}, M_{i}, W_{i}$ ), information regarding rain profile (i.e. precipitation) and water salinity level were also provided on a hourly basis and denoted as $r_{i}$ and $\ell_{i}$ respectively

${ }^{5}$ http://www.shom.fr/ 
for $1 \leq i \leq 24 * N_{\text {days }}$. The valve opening data $P_{i, j}$ being used in our current work differs from that of our previous work [12]. In [12], we considered the opening/closing of valve based on threshold. Based on a selected threshold, the opening of the valve (in percentage) during one hour was calculated for our previous work. This clearly distinguishes our current work with that of previous one since here we consider the actual distance instead of using any threshold to determine the relative activity of an oyster. Moreover, precipitation and water salinity level information are also being considered in our current work for the model identification which were not used in our previous work [12].

The first problem that arises while dealing with the valve distance data is that its length is not uniform all through the year. Like almost every other animal, the size of oysters also changes as time passes by. We need to normalize the data between certain bound so that the effect of change of length of distance can be compensated. The normalization was done considering a 6 days window and with a bound $[0,1]$, where 0 represents complete closing of the valve while 1 represents complete opening of the valve. The formula to calculate the normalized value is:

$$
p_{i, j}=\frac{P_{i, j}-\min _{a=i-N_{t}, \cdots, i}\left(P_{a, j}\right)}{\max _{a=i-N_{t}, \cdots, i}\left(P_{a, j}\right)-\min _{a=i-N_{t}, \cdots, i}\left(P_{a, j}\right)}
$$

where $N_{t}$ is the total number of data points in last 6 days, $P_{i, j}$ is the actual valve distance and $p_{i, j}$ is the normalized valve distance [38]. The next question that arises is how to use the data of 16 different oysters for the model identification of the population. The normalized valve distance of three different oysters can be seen in Fig.4. From this figure, it can be observed that although the behavior of all these oysters are not exactly the same but the correlation between the behaviors is also not that weak ${ }^{6}$. So, averaging the behavior of all oysters can be a good way to capture the dynamics of the population. Since $N \approx 2 \times 10^{7}$, to simplify the computation and the presentation in this study, the measurements have been averaged on hourly basis i.e. define $\delta N=\frac{3600[\mathrm{sec}]}{1.6[\mathrm{sec}]}=2250$ and $L=\frac{N}{\delta N}$, then for all $1 \leq j \leq n$ :

$$
\begin{aligned}
p_{k, j} & =\delta N^{-1} \sum_{q=(k-1) \delta N+1}^{k \delta N} P_{q, j}, \\
s_{k} & =\delta N^{-1} \sum_{q=(k-1) \delta N+1}^{k \delta N} S_{q}, \\
m_{k} & =\delta N^{-1} \sum_{q=(k-1) \delta N+1}^{k \delta N} M_{q}, \\
w_{k} & =\delta N^{-1} \sum_{q=(k-1) \delta N+1}^{k \delta N} W_{q},
\end{aligned}
$$

corresponds to hourly averaged opening of the valves, the sun and moon positions, the water level respectively. The examples of obtained signal $s_{k}, m_{k}$ and $w_{k}$ are shown in Fig.5a. In Fig. $5 b$, the frequency spectrum of these periodic/quasi periodic

\footnotetext{
${ }^{6}$ The correlation coefficient of oyster 1 with respect to oyster $2,3, \ldots, 16$ are $0.4474,0.5651,0.4811,0.5335,0.3739,0.4824,0.3504,0.4654,0.2446$, $0.1083,0.4606,0.2378,-0.181$ and 0.3871 respectively.
}

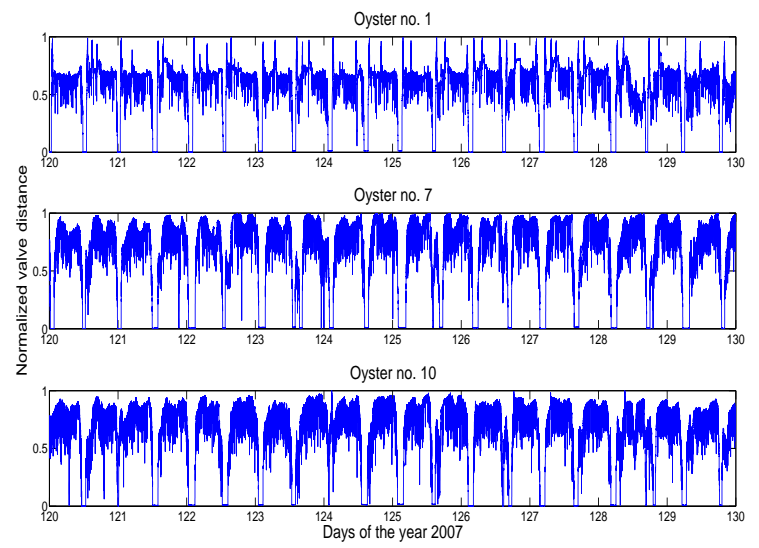

Figure 4. Examples of normalized valve distance of three oysters during 10 days (sampling period, $T_{s}=1.6 \mathrm{sec}$.)

signals can be seen. Finally, precipitation and water salinity level information are shown in Fig. 6.

The averaged opening position of valves, on an hourly basis, for the investigated population of oysters can be defined as:

$$
h_{k}=n^{-1} \sum_{j=1}^{n} p_{k, j}
$$

The averaged valve opening of the population $h_{k}$ can be seen in Fig. 7.

From the plot, it can be easily inferred that the opening average of valves on hourly basis for the population $h_{k}$ has a more regular and smoother behavior than individual ones. This behavior leads us to consider the signal $h_{k}$ as a suitable choice for forthcoming analysis and model identification. Thus an averaged physiological population dynamics has to be modeled and identified for oysters. An additional motivation for this choice is standard in modeling biological systems: each individual exhibits a proper variability according to stochastic exogenous and endogenous forces, which are hard to predict or measure, while averaged signal $h_{k}$ is less sensitive to these perturbations and represents mainly the regular physiological behavior of the animals. Naturally, this is especially true if the population size $n$ is big (this is not the case in the considered application due to various experimental complexities forcing us to limit the population size to 16). Another alternative to averaging can be using population models similar to what is developed to characterize the effect of drug treatments [39], [40]. However, those models require larger population size and heterogeneity among the animals. In our case, the population size is very small. Moreover, the oysters are not very heterogeneous. They all are of same age group (1.5 years), collected from the same local supplier and were raised in the same place (bay of Arcachon). Also, the correlation among the oysters is not weak as well. All the inputs of our model (water salinity, water level etc.) were also available on an hourly basis. Thus, hourly averaging is natural in our case.

It is known [35] that the opening activity of oysters $h_{k}$ is externally governed by the sunlight, moon oscillations and the tide activity, denoted here by $s_{k}, m_{k}$ and $w_{k}$ respectively. Moreover, precipitation $\left(r_{k}\right)$ and the salinity level in the water 

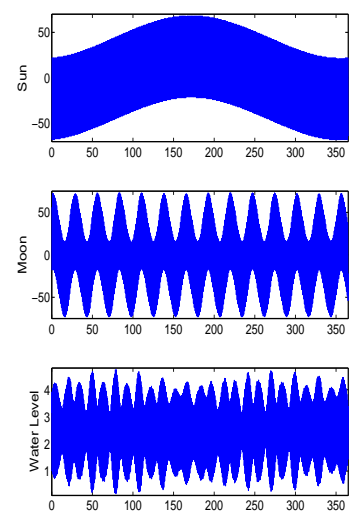
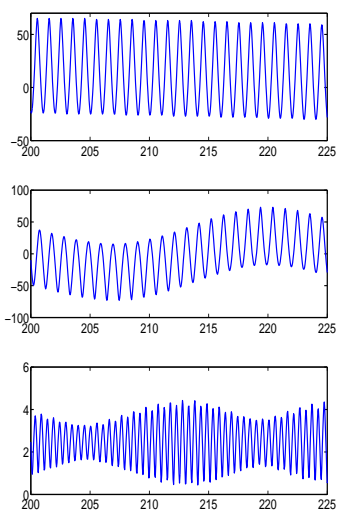

a)
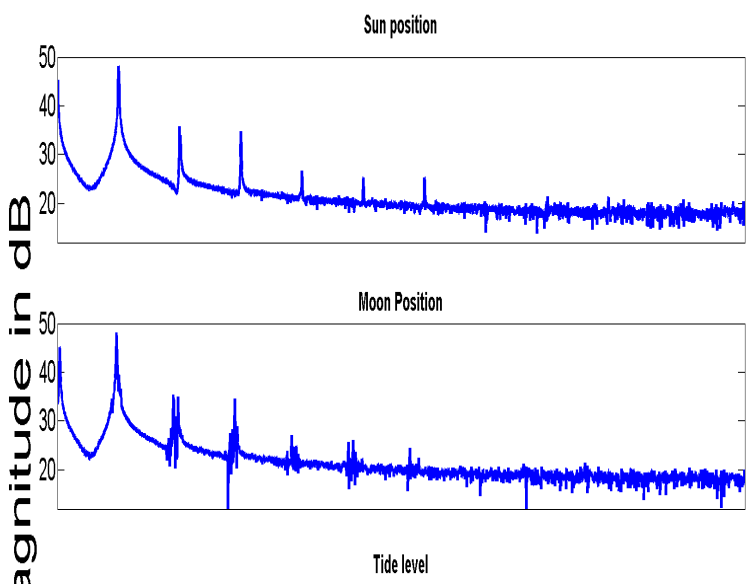

b)

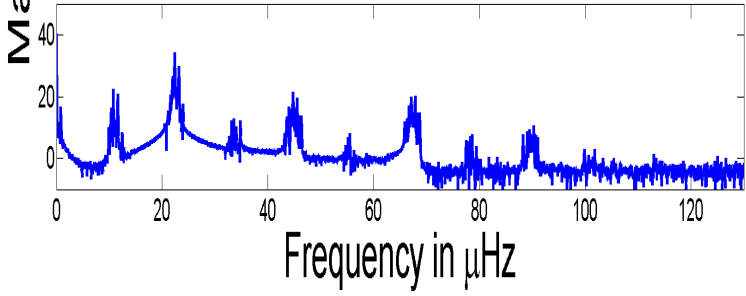

Figure 5. a) Sun and moon position, tide level (left column-original signal, right column-zoomed version) during a whole year (2007) b) Frequency spectrum of the signals.
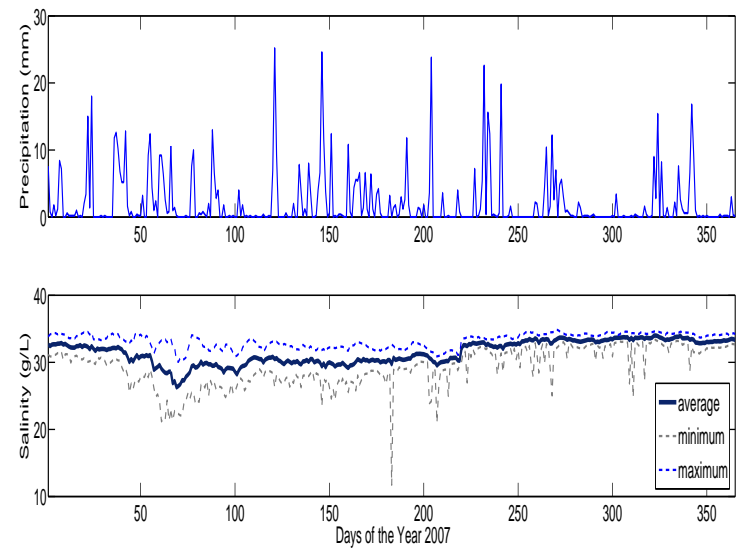

Figure 6. Precipitation (top) and water salinity level (bottom) during the year 2007 (one data point each day)

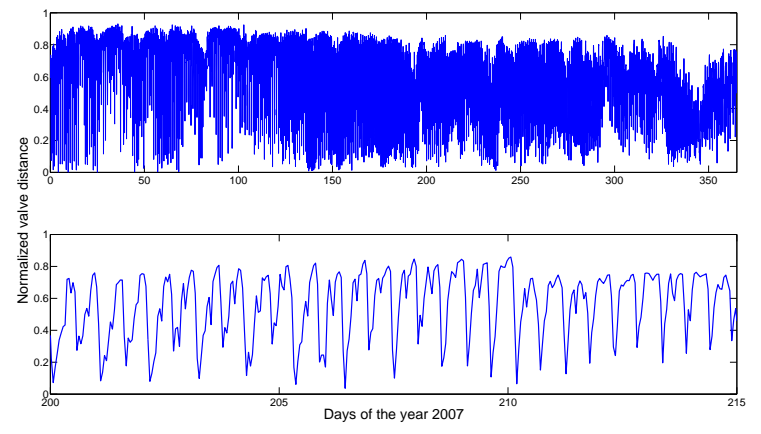

Figure 7. Hourly averaged valve opening of the population (top-original signal, bottom-zoomed version) (one data point each hour)

$\left(\ell_{k}\right)$ may also have an external impact on the opening activity of oysters. Other sources of rhythmicity are internal (feeding, breathing etc.) and supervised by internal clocks. The reference signal generated by circadian rhythm genetics, which is directly influencing $h_{k}$, will be denoted by $c_{k}$. The generic structure of a dynamical physiological model for population of oysters can be presented as follows [12] :

$$
\begin{aligned}
h_{k}= & F\left(h_{k-1}, \ldots, h_{k-\nu}, s_{k}, \ldots s_{k-\mu}\right. \\
& m_{k}, \ldots m_{k-\mu}, w_{k}, \ldots w_{k-\mu}, r_{k}, \ldots r_{k-\mu} \\
& \left.\ell_{k}, \ldots \ell_{k-\mu}, c_{k}, \ldots c_{k-\mu}, \theta\right)+\epsilon_{k} \\
c_{k}= & D\left(\xi_{k}\right) \\
\xi_{k}= & G\left(\xi_{k-1}, s_{k}, \ldots s_{k-\mu}, m_{k}, \ldots m_{k-\mu}\right. \\
& \left.w_{k}, \ldots w_{k-\mu}\right)
\end{aligned}
$$

where $\nu \geq 0$ represents the number of past events taken into account by the animals in order to determine the opening distance at the next time instant $k$ (i.e. in this model $k-1$ is the current time instant and $h_{k-1}$ is the current valve state); $\mu \geq 0$ is the number of previous values for the positions of sun/moon, tide levels, precipitation and water salinity levels that are used in the decision on the value of $h_{k}$ (the model (6) assumes that the instant values of $s_{k}, m_{k}, r_{k}, \ell_{k}$ and $w_{k}$ can be used for this decision); $\epsilon_{k} \in \mathbb{R}$ is the disturbance representing additional uncertain influencing forces and approximation errors (it is assumed that this term is sufficiently small if the model has been well identified); $\theta \in \mathbb{R}^{q}$, $q>0$ is the vector of constant parameters of the model (6), and $F: \mathbb{R}_{+}^{\nu+6 \mu+6+q} \rightarrow \mathbb{R}_{+}$is a function defining the physiological model structure; $\xi_{k} \in \mathbb{R}^{p}$ is the state of the circadian oscillator (7); the functions $G: \mathbb{R}^{p+3 \mu+3} \rightarrow \mathbb{R}^{p}$ and $D: \mathbb{R}^{p} \rightarrow \mathbb{R}$ define the structure of the circadian rhythm model (7). The model (7) assumes that circadian oscillations are entrained by the external cues $s_{k}, m_{k}$ and $w_{k}$ (some of them depending on the type of the rhythm under consideration, see below). The structure scheme of the model is given in Fig. 8.

The identification procedure consists in selecting an appropriate structure for the physiological model $F(\cdot)$ and the circadian model $G(\cdot), D(\cdot)$, with posterior calculation of the corresponding vector of parameters $\theta$.

Further in this section two problems are considered. First, the issue of circadian rhythms modeling is discussed and a solution 


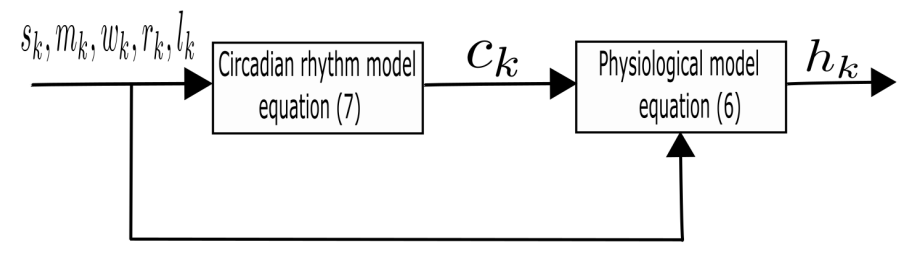

Figure 8. Structure scheme of the generic model (6), (7)

is proposed. Second, an ARMAX structure is selected for $F(\cdot)$ and the corresponding model is designed.

\section{A. Models of circadian clocks}

A rhythm in chronobiology is a biological process that displays an endogenous and self-sustained oscillation with a period of about 24 hours, for instance the circadian rhythm. These rhythms are driven by an internal clock, i.e. by a biochemical embedded mechanism. Their main properties are the generation of periodic rhythms, endogeneity, adaptability to a local environment by external forces called zeitgebers (the most important one being daylight for terrestrial animals), and robustness over a range of physiological temperatures. Rhythms have been observed in almost all forms of living organisms, from cyanobacteria and plants to mammals. The science of biological temporal rhythms, such as solar and lunar related rhythms, is called chronobiology [41][42].

1) Hypothesis on clocks: There exist many mathematical models of clocks mechanisms [43], [44], [45], [46]. Different hypothesis on the nature of clocks presented in oysters [35] have been issued, but not yet supported by a mathematical model. First, as many animals, the oysters may have circadian oscillations with the period of 24 hours synchronized by sunlight (i.e. circadian clock). Second, as animals living in a tidal ecosystem, they may also have a second rhythm with the period 12.4 hours and entrained by tides, which may be driven by a circatidal clock. Third, the oyster rhythms may be regulated by the moon with the period 24.8 hours under the control of circalunidian clocks. The diversity of hypothesis follows the variety of habitation areas of bivalves, e.g. arctic zones (where the sunlight may have approximately constant intensity during several months), open ocean conditions with strong tides or Mediterranean bays, where tides are almost negligible. Finally, this motivates the fourth hypothesis: a unique "circadian/circatidal" clock, synchronized by sunlight and tides, generating a bimodal rhythm running from 12.4 to 24.8 hours depending on the local biotope conditions. Among several different cases regarding the nature of the circadian clock, we have considered two hypothesis in our current work, namely:

1) Hypothesis 1 (H1): The rhythm of the oysters is governed mostly by a circadian clock in response to sunlight.

2) Hypothesis $2(\mathrm{H} 2)$ : The rhythm of the oysters is governed mostly by a circatidal clock and a circadian clock in response to the tide level and sunlight simultaneously.

The structure scheme of the model for the two different hypothesis is given in Fig. 9. Based on these two hypothesis, the corresponding mathematical models are developed below.
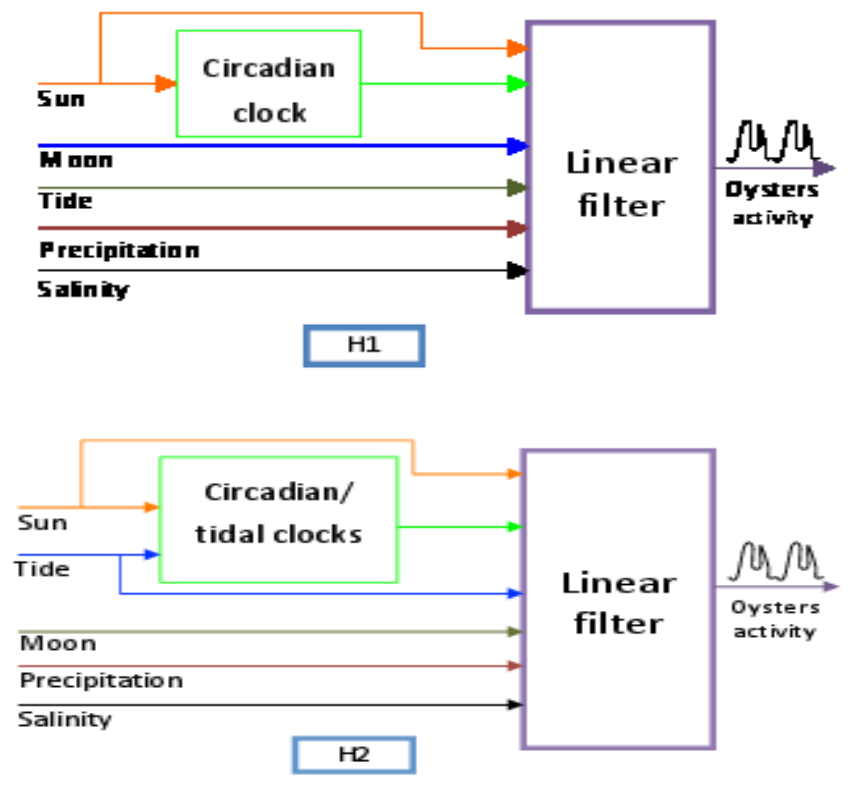

Figure 9. Structure scheme of the model for $\mathrm{H} 1$ and $\mathrm{H} 2$

Conventional models of oscillators [43], [44], [45] have different complexity. There exist also methods to design generic oscillating systems [47] of any complexity. However, as it was observed in [48], [49] any oscillating system on the limit cycle can be fully characterized by its current phase and the form of limit cycle (i.e. amplitude of oscillations). Therefore, if an exact genetic or biochemical nature of oyster oscillations is not clear, then in order to preserve the model simplicity, the oyster rhythm can be represented by any oscillator, and a particular attention has to be paid to a relation of the phase of this oscillator and environmental rhythms. In [50], [48] variants of Van der Pol oscillator [51] have been used for modelization of circadian rhythms for different animals. Van der Pol oscillator has a simple planar mathematical model with just two parameters that allows the form of the limit cycle and the period of oscillations to be tuned:

$$
\begin{aligned}
& \dot{\xi}_{1}=\alpha\left[\xi_{2}+\mu\left(\xi_{1}-\frac{4}{3} \xi_{1}^{3}\right)+u\right], \\
& \dot{\xi}_{2}=-\alpha \xi_{1},
\end{aligned}
$$

where $\xi_{1} \in \mathbb{R}$ and $\xi_{2} \in \mathbb{R}$ are the model states, $\alpha>0$ determines the model oscillation velocity (adjustment of this parameter regulates the period of oscillation for the model); $\mu>0$ is a parameter to determine the shape of oscillations ( $\mu \approx 0$ for almost harmonic oscillations, $\mu \geq 2$ leads to a nonlinear profile); $u \in \mathbb{R}$ is the model input that can be used for the entrainment. In our case the parameter $\alpha$ has to be selected in order to ensure the period of oscillations of 24 hours for the first hypothesis and 24.8 for the third one, for instance. The form of oscillations on the limit cycle, i.e. the value of parameter $\mu$, is less important since in the model (6), (7) the shape of $c_{k}$ can be taken into account later in the function $F(\cdot)$ and by tuning the parameters $\theta$ (the value $\mu=2$ is used in this work for all computations). Therefore, the functions $G(\cdot)$ and $D(\cdot)$ in (7) can 
be defined based on Van der Pol equations discretized using the Euler method:

$$
\begin{aligned}
\xi_{1, k} & =\xi_{1, k-1}+T \alpha\left[\xi_{2, k-1}+\mu\left(\xi_{1, k-1}-\frac{4}{3} \xi_{1, k-1}^{3}\right)+u_{k}\right], \\
\xi_{2, k} & =\xi_{2, k-1}-T \alpha \xi_{1, k-1}, \\
c_{k} & =\max \left\{0, \xi_{1, k}\right\}
\end{aligned}
$$
where $T=1$ hour is the sampling time, $c_{k}$ is the positive part of $\xi_{1}$ and $u_{k}$ is the resetting input, which has to be specified.

The entrainment regulates the phase of oscillations (synchronizes the exogenous cues and endogenous rhythms), the mechanism of entrainment and phase resetting can be well analyzed using the Phase Response Curve approach [49], [52]. For example, for the first hypothesis we select $u_{k}=$ $\rho \max \left\{0, s_{k}\right\} / \max _{1 \leq k \leq L}\left|s_{k}\right|$, where $\rho>0$ is the scaling parameters that is selected in order to harmonize the amplitude of the input $u_{k}$ and the dimension of the limit cycle. The selection $\max \left\{0, s_{k}\right\}$ is applied since for the oyster rhythm the daylight is the principal zeitgeber, and the light is emitted when the sun is above the horizon only. For the first hypothesis, $u_{k}=s_{k}$, is the position of the sun. While for the second hypothesis, $u_{k}$ has the following form:

$$
u_{k}=\left[\lambda_{s} \lambda_{w}\right]\left[s_{k} w_{k}\right]^{T}
$$

where $\lambda_{s}$ and $\lambda_{w}$ are the weights regulating the influence of sun position $s_{k}$ and tide level $w_{k}$ on the circadian oscillation. For the second hypothesis, in addition to the sunlight, we have also tide/water level as zeitgeber. In order to harmonize the amplitude of the water level, we have selected $w_{k}$ as $w_{k}=$ $\rho w_{k} / \max _{1 \leq k \leq L}\left|w_{k}\right|$.

To generate the signal $c_{k}$ using the proposed model it is necessary to properly assign the initial phase for the oyster clock model (initial position on the limit cycle), which has to be coordinated with the current zeitgebers activity. A possible solution is to apply to the model the input patterns extracted from the first month of the experiment (or the last one in our case, since the experiment duration is 1 year and the inputs-sun position, moon position and the tide level have annual periodicity) several times in order to entrain the oscillator.

\section{B. ARMAX model}

The ARMAX (auto-regressive-moving-average with exogenous inputs) model is one of the most popular structures used for identification in various fields of science [53], [54], [55]. Its advantages include linearity with respect to all signals and parameters, different effective methods for calculation of the parameters, simplicity of stability analysis of the obtained model, robustness and sensitivity with respect to perturbations. Therefore, the function $F(\cdot)$ in (6) is selected in the following form:

$$
\begin{aligned}
F(\cdot)= & \sum_{i=1}^{\nu} \theta_{i}^{h} h_{k-i}+\sum_{j=0}^{\mu} \theta_{i}^{s} \tilde{s}_{k-j}+\sum_{j=0}^{\mu} \theta_{i}^{m} \tilde{m}_{k-j} \\
& +\sum_{j=0}^{\mu} \theta_{i}^{w} w_{k-j}+\sum_{j=0}^{\mu} \theta_{i}^{r} r_{k-j} \\
& +\sum_{j=0}^{\mu} \theta_{i}^{\ell} \ell_{k-j}+\sum_{j=0}^{\mu} \theta_{i}^{c} c_{k-j},
\end{aligned}
$$

(9) ${ }_{\text {where }}$ the positive values $\tilde{s}_{k}=\max \left\{0, s_{k}\right\}$ and $\tilde{m}_{k}=$

$$
\begin{aligned}
\theta= & {\left[\theta_{1}^{h}, \ldots, \theta_{\nu}^{h}, \theta_{0}^{s}, \ldots, \theta_{\mu}^{s}, \theta_{0}^{m},\right.} \\
& \ldots, \theta_{\mu}^{m}, \theta_{0}^{w}, \ldots, \theta_{\mu}^{w}, \theta_{0}^{r}, \ldots, \theta_{\mu}^{r}, \\
& \left.\theta_{\mu}^{\ell}, \ldots, \theta_{\mu}^{\ell}, \theta_{0}^{c}, \ldots, \theta_{\mu}^{c}\right]^{T},
\end{aligned}
$$
$\max \left\{0, m_{k}\right\}$ of the signals $s_{k}$ and $m_{k}$ respectively are used to model an influence of the sunlight and moonlight (the sun and the moon are above the horizon and deliver the light when $s_{k}$ and $m_{k}$ are positive only). Formally the proposed function $F(\cdot)$ is nonlinear with respect to its arguments $s_{k}$ and $m_{k}$ (it contains $\max \{\cdot\}$ ). The nonlinear model under consideration including the effect of circadian clock has the NARX structure (6), (7) for the selected $F(\cdot)$ and $G(\cdot), D(\cdot)$. A summary of NARX type model can be found in [56], [57].

\section{HYPOTHESIS SELECTION, VERIFICATION AND ANALYSIS}

Using the Least Square method [54], [55], [53], the estimates $\hat{\theta}$ of the parameters $\theta$ have been calculated for the dataset collected at the Eyrac pier, the Bay of Arcachon, France, 2007:

$$
\hat{\theta}=\left(\Phi^{T} \Phi\right)^{-1} \Phi^{T} \Upsilon
$$

where $\Upsilon=\left[h_{\nu+1}, \ldots h_{L}\right]^{T}$ and the $j$ th row of the matrix $\Phi$,

$$
\begin{aligned}
\Phi_{j}= & {\left[h_{j+\nu-1}, \ldots, h_{j}, \tilde{s}_{j+\nu}, \ldots, \tilde{s}_{j+\nu-\mu},\right.} \\
& \tilde{m}_{j+\nu}, \ldots, \tilde{m}_{j+\nu-\mu}, w_{j+\nu}, \ldots, w_{j+\nu-\mu}, \\
& r_{j+\nu}, \ldots, r_{j+\nu-\mu}, \ell_{j+\nu}, \ldots, \ell_{j+\nu-\mu}, \\
& \left.c_{j+\nu}, \ldots, c_{j+\nu-\mu}\right]
\end{aligned}
$$

for all $1 \leq j \leq L-\nu$.

\section{A. Hypothesis selection}

In III-A1, we have considered two different hypothesis, namely H1 \& H2. Performance comparison of models based on H1 and $\mathrm{H} 2$ with experimental data can be seen in Fig. 10. From these results, no definitive conclusion can be drawn regarding the superiority or inferiority of any individual hypothesis. Both of them are almost identical. We are working with oysters living in real-life situation i.e. in the sea, therefore oysters behaviors are influenced by a multitude of factors (and not only by the sun and moon position or water tide or precipitation or water salinity level). Hence, our suggestion in this case is that the effect of different cyclic inputs on oysters, like circadian clocks, might be better observed if we can place them in a controlled laboratory environment. In that case, we can experiment with individual inputs and will be able to observe the response of oysters to that input. However, in our current situation we think that the second hypothesis is more realistic than the first one as it involves both sunlight and tide at the same time. For marine animals, to consider the effect of tide along with sunlight on internal clocks is a very natural choice. So, for further analysis, we have selected the model based on hypothesis 2 .

In hypothesis 2, the internal clock of oysters is influenced by sunlight and tide at the same time. So, a natural question is: what is the impact of individual inputs (sunlight and tide) on the behavior of oysters? To attempt to answer this question, we 


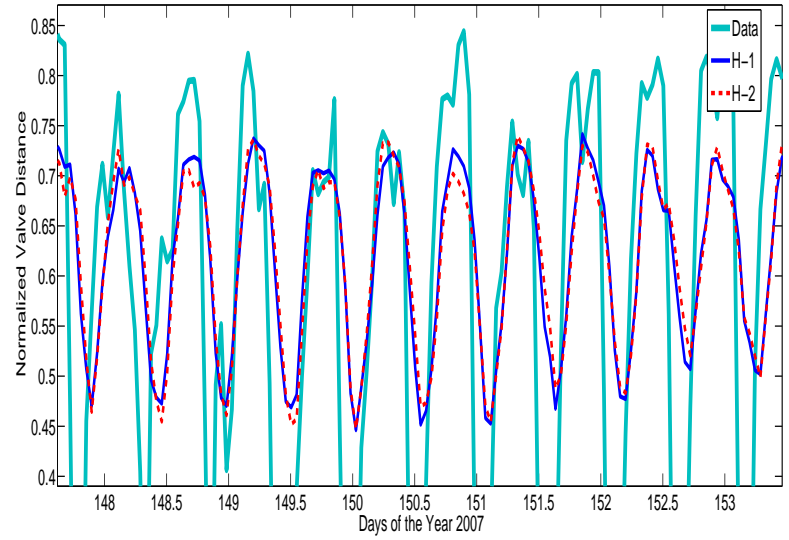

Figure 10. Comparative performance of two different hypothesis based model with actual data

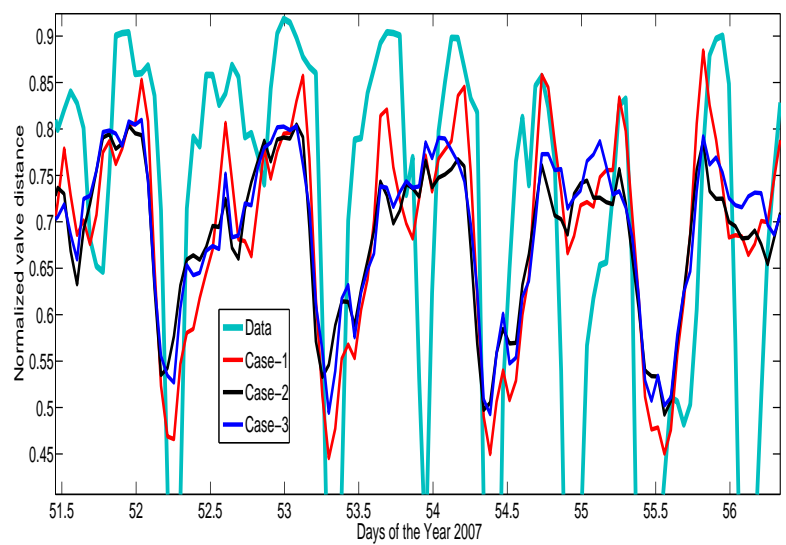

Figure 11. Impact of sunlight $\&$ tide level on the behavior of oysters

have considered three different situations. First, in case 1, we assumed that both inputs have equal weights i.e. $\lambda_{s}=\lambda_{w}=0.5$. Second, in case 2 , more weights on tide level were considered $\left(\lambda_{w}=0.75, \lambda_{s}=0.25\right)$. Finally, in case 3 , more weights on sunlight were imposed $\left(\lambda_{w}=0.25, \lambda_{s}=0.75\right)$. The impact of these three cases on oysters can be seen in Fig. 11. From this figure, it can be seen that the performance of the model based on equal weights has better performance than the other two cases. Following this observation, we have considered equal weights on both sunlight and tide level for further analysis \& verification.

\section{B. Verification}

To evaluate the obtained accuracy of the designed model two performance costs $J_{\epsilon}$ and $J_{p}$ have been calculated. The cost $J_{\epsilon}$ estimates the average amplitude of $\epsilon_{k}$ (the approximation errors in the model): $\epsilon_{j}=h_{j+\nu}-\hat{h}_{j+\nu}, \hat{h}_{j+\nu}=\Phi_{j}^{T} \hat{\theta}, 1 \leq j \leq L-\nu$ and

$$
J_{\epsilon}=\sqrt{\frac{\sum_{j=1}^{L-\nu} \epsilon_{j}^{2}}{L-\nu}} .
$$

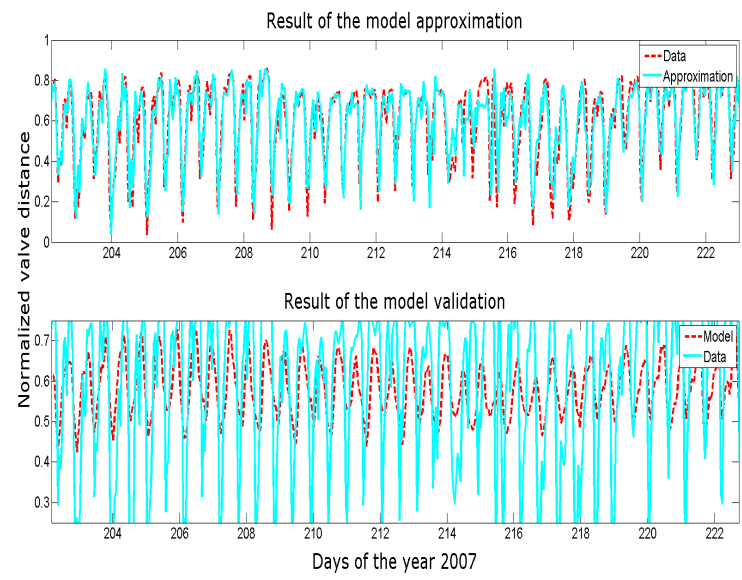

Figure 12. The results of the model numerical verification

The cost $J_{p}$ evaluates the prediction quality of the model on an infinite time interval: $e_{j}=h_{j+\nu}-\tilde{h}_{j+\nu}, 1 \leq j \leq L-\nu$ and

$$
\begin{aligned}
J_{p}=\sqrt{\frac{\sum_{j=1}^{L-\nu} e_{j}^{2}}{L-\nu}} \text { where } \\
\tilde{h}_{k}=h_{k}, \quad 1 \leq k \leq \nu, \\
\tilde{h}_{\nu+j}=\sum_{i=1}^{\nu} \theta_{i}^{h} \tilde{h}_{\nu+j-i}+\sum_{z=0}^{\mu} \theta_{i}^{s} \tilde{s}_{\nu+j-z} \\
+\sum_{z=0}^{\mu} \theta_{i}^{m} \tilde{m}_{\nu+j-z}+\sum_{z=0}^{\mu} \theta_{i}^{w} w_{\nu+j-z} \\
+\sum_{z=0}^{\mu} \theta_{i}^{r} r_{\nu+j-z}+\sum_{z=0}^{\mu} \theta_{i}^{\ell} \ell_{\nu+j-z} \\
+\sum_{z=0}^{\mu} \theta_{i}^{c} c_{\nu+j-z}, \quad 1 \leq j \leq L-\nu
\end{aligned}
$$

are the estimates of the valve positions $h_{k}$ generated independently by the designed model in the presence of the same inputs. Examples of the obtained estimates $\hat{h}_{k}$ and $\tilde{h}_{k}$ (for $\nu=\mu=72$, i.e. the oysters have 3 days of memory) for the second hypothesis are shown in Fig. 12, with performance costs $J_{\epsilon}=0.08$ and $J_{p}=0.19$. We conclude from this example that the model demonstrates a sufficiently good accuracy of representation of the physiological behavior of oysters.

\section{Application to ecological monitoring}

As it has been noted in the Introduction, ecological monitoring is in some part expensive and invasive of the environment under study (an extensive or poorly planned monitoring carries a risk of environmental degradation). This fact may be critical in wilderness areas or those that are averse to human presence. Some monitoring techniques may be very damaging, at least to the local population and can also degrade public trust in scientists carrying out the monitoring. That is why remote sensing and mathematical modeling become very important. Obviously, the application of a far-reaching mathematical modeling can reduce the cost of monitoring, while improving its safety and accuracy. 


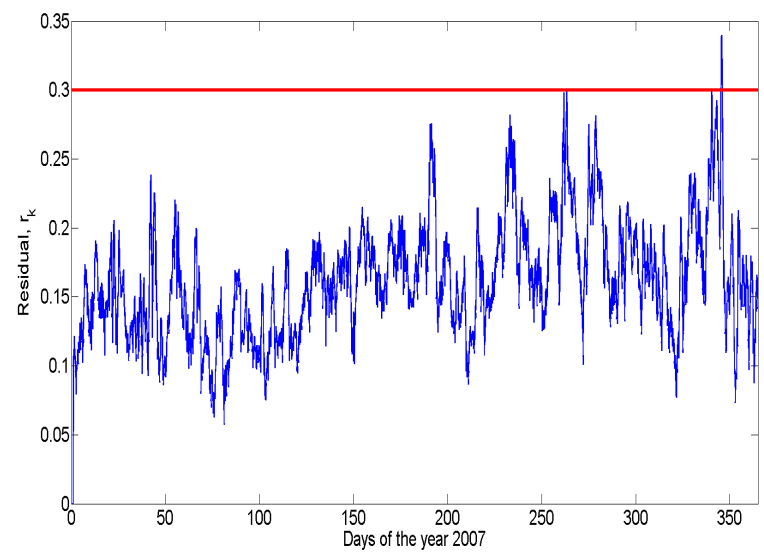

Figure 13. Residual for water quality monitoring

The area of population of bivalves is rather large, and the developed physiological model can serve for water quality monitoring, if we would compare the real measurements $h_{k}$ obtained by an embedded electronic unit on a bay and the estimates provided by the model $\tilde{h}_{k}$. For example, the following daily monitoring residual can be computed:

$$
r_{k}=\frac{1}{24} \sum_{z=0}^{23}\left|h_{k-z}-\tilde{h}_{k-z}\right|
$$

for all $24 \leq k \leq L$, where an averaging on 24 hours is used in order to decrease sensitivity of the residual with respect to measurement noises. For the dataset collected at the Eyrac pier in 2007, the obtained residual $r_{k}$ is shown in Fig. 13. It is worth to stress that the Eyrac pier in the Bay of Arcachon is located in a fairly clean and well-protected area, but as we can see, the residual presented a peek value at the beginning of the December 2007. In fault detection literature [58], [59], [60], [61], the peak is known as fault (i.e. deviation from normal behavior). So, the detection of this fault is equivalent to the detection of pollution. The peak actually corresponds to a time period of heavy rain. Since the output of a storm sewer is located at about 10-15 meters from the oysters and as there was no change of salinity at that precise time (Fig. 6 bottom), we suggest that some unknown contaminant, washed by the rain, could have reach them. This simple case study justifies the utility of the developed approach in automated systems tracking silent pollution.

\section{Conclusion}

The paper presents the first development of a dynamical physiological model for oysters, which takes into account an influence of external cycles (daylight, moonlight and tides), externally influencing factors (like precipitation and water salinity level) and internal clocks as well. A generic "black-box" modeling approach has been used, and NARX structure of the model has been selected. It properly fits with the idea that the clock mechanism in oysters is drive by tide and sunlight simultaneously. The obtained model has been successfully applied for automatically and fast detecting an abnormal deviation of behavior which occurred following a rainy period in Arcachon, France.
A limitation of this work lies in the fact that it can not highlight/isolate the source of abnormalities. Moreover, there are abnormalities which are not related to pollution. One example is spawning i.e., the behaviour of the female oysters during reproduction [38]. So, to determine the origin of the abnormalities could be considered for future work. One way of dealing this problem would be to observe the behaviour of oysters in response to various kinds of pollutants in the laboratory environment.

Acknowledgment: The authors thank Ifremer Arcachon and Isabelle Auby for kindly providing precipitation and salinity data for the Eyrac pier, Bay of Arcachon, 2007.

\section{REFERENCES}

[1] A. Mimendia, J. M. Gutierrez, L. Leija, P. R. Hernandez, L. Favari, R. Munoz, and M. Del Valle, "A review of the use of the potentiometric electronic tongue in the monitoring of environmental systems," Environmental Modelling \& Software, vol. 25, no. 9, pp. 1023-1030, 2010.

[2] L. K. Pandey, D. Kumar, A. Yadav, J. Rai, and J. Gaur, "Morphological abnormalities in periphytic diatoms as a tool for biomonitoring of heavy metal pollution in a river," Ecological Indicators, vol. 36, pp. 272-279, 2014.

[3] K. A. Rose, R. I. McLean, and J. K. Summers, "Development and monte carlo analysis of an oyster bioaccumulation model applied to biomonitoring data," Ecological Modelling, vol. 45, no. 2, pp. 111-132, 1989.

[4] E. Cabecinha, R. Cortes, and J. A. Cabral, "Performance of a stochasticdynamic modelling methodology for running waters ecological assessment," Ecological modelling, vol. 175, no. 3, pp. 303-317, 2004.

[5] E. Cabecinha, P. Silva-Santos, R. Cortes, and J. A. Cabral, "Applying a stochastic-dynamic methodology (stdm) to facilitate ecological monitoring of running waters, using selected trophic and taxonomic metrics as state variables," Ecological Modelling, vol. 207, no. 2, pp. 109-127, 2007.

[6] S. Jorgensen, "A general model for the heavy metal pollution of aquatic ecosystems: Model development," Environmental Software, vol. 5, no. 3, pp. 136-141, 1990.

[7] I. James, "Modelling pollution dispersion, the ecosystem and water quality in coastal waters: a review," Environmental Modelling \& Software, vol. 17, no. 4, pp. 363-385, 2002.

[8] T. Telfer, H. Atkin, and R. Corner, "Review of environmental impact assessment and monitoring in aquaculture in europe and north america," in Environmental impact assessment and monitoring in aquaculture, ser. Fish Aquac Tech Pap No. 527, FAO. Rome: UN FAO, 2009, pp. 285394.

[9] S. Kröger and R. Law, "Sensing the sea," Trends in Biotechnology, vol. 23, pp. 250-256, 2005.

[10] S. Tlili, L. Minguez, L. Giamberini, A. Geffard, H. Boussetta, and C. Mouneyrac, "Assessment of the health status of donax trunculus from the gulf of tunis using integrative biomarker indices," Ecological Indicators, vol. 32, pp. 285-293, 2013.

[11] G. Galang, C. Bayliss, S. Marshall, and R. O. Sinnott, "Real-time detection of water pollution using biosensors and live animal behaviour models," in eResearch Australasia: emPower eResearch, Sydney, Australia, 2012.

[12] H. Ahmed, R. Ushirobira, D. Efimov, D. Tran, and J.-C. Massabuau, "Dynamical model identification of population of oysters for water quality monitoring," in Control Conference (ECC), 2014 European, June 2014, pp. 152-157.

[13] F. Marceau, "Contraction of molluscan muscle," Arch. Zool. Exp. Gen., vol. 2, pp. 295-469, 1909.

[14] K. J. M. Kramer, H. A. Jenner, and D. De Zwart, "The valve movement response of mussels: A tool in biological monitoring," Hydrobiologia, vol. 188/189, pp. 433-443, 1989.

[15] J. Borcherding, The Zebra Mussel Dreissena Polymorpha: Ecology, Biological Monitoring and First Applications in the Water Quality Management. NY: Gustav Fischer Verlag, 1992, ch. Another early warning system for the detection of toxic discharges in the aquatic environment based on valve movements of the freshwater mussel Dreissena polymorpha, pp. 127-146.

[16] $\_$, "Ten years of practical experience with the dreissena-monitor, a biological early warning system for continuous water quality monitoring," Hydrobiologia, vol. 556, no. 1, pp. 417-426, 2006. 
[17] A. Robson, R. Wilson, and C. Garcia de Leaniz, "Mussels flexing their muscles: A new method for quantifying bivalve behavior," Marine Biology, vol. 151, pp. 1195-1204, 2007.

[18] J. Garcia-March, M. Sanchis Solsona, and A. GarciaCarrascosa, "Shell gaping behavior of pinna nobilis 1., 1758: Circadian and circalunar rhythms revealed by in situ monitoring," Marine Biology, vol. 153, pp. 689-698, 2008

[19] A. Beyene, A. Awoke, and L. Triest, "Validation of a quantitative method for estimating the indicator power of, diatoms for ecoregional river water quality assessment," Ecological Indicators, vol. 37, pp. 58-66, 2014.

[20] D. Tran, P. Ciret, A. Ciutat, G. Durrieu, and J. Massabuau, "Estimation of potential and limits of bivalve closure response to detect contaminants: Application to cadmium," Environ. Toxicol. Chem., vol. 22, pp. 116-122, 2003.

[21] M. Sow, G. Durrieu, L. Briollais, P. Ciret, and J.-C. Massabuau, "Water quality assessment by means of hfni valvometry and high-frequency data modeling," Environmental Monitoring and Assessment, vol. 182, no. 1-4, pp. 155-170, 2011.

[22] F. G. Schmitt, M. De Rosa, G. Durrieu, M. Sow, P. Ciret, D. Tran, and J.C. Massabuau, "Statistical study of bivalve high frequency microclosing behavior: Scaling properties and shot noise analysis," International Journal of Bifurcation and Chaos, vol. 21, no. 12, pp. 3565-3576, 2011.

[23] A. Luna-Acosta, P. Bustamante, H. Budzinski, V. Huet, and H. ThomasGuyon, "Persistent organic pollutants in a marine bivalve on the marennes-oléron bay and the gironde estuary (french atlantic coast)part 2: Potential biological effects," Science of The Total Environment, vol. 514, pp. 511-522, 2015.

[24] A. Luna-Acosta, H. Budzinski, K. Le Menach, H. Thomas-Guyon, and P. Bustamante, "Persistent organic pollutants in a marine bivalve on the marennes-oleron bay and the gironde estuary (french atlantic coast)-part 1: Bioaccumulation," Science of The Total Environment, vol. 514, pp. 500-510, 2015.

[25] T. Palmer, P. Uehling, and J. Pollack, "Using oyster tissue toxicity as an indicator of disturbed environments," International Journal of Environmental Science and Technology, vol. 12, no. 6, pp. 2111-2116, 2015.

[26] C. Aguilar, C. Montalvo, L. Rodriguez, J. Ceron, and R. Ceron, "American oyster (crassostrea virginica) and sediments as a coastal zone pollution monitor by heavy metals," International Journal of Environmental Science and Technology, vol. 9, no. 4, pp. 579-586, 2012.

[27] V. Englund and M. Heino, "Valve movement of anodonta anatina and unio tumidus (bivalvia, unionidae) in a eutrophic lake," in Annales Zoologici Fennici, vol. 31, no. 2, 1994, pp. 257-262.

[28] K. D. Ham and M. J. Peterson, "Effect of fluctuating low-level chlorine concentrations on valve-movement behavior of the asiatic clam (corbicula fluminea)," Environmental toxicology and chemistry, vol. 13, no. 3, pp. 493-498, 1994.

[29] V. P. Englund and M. P. Heino, "Valve movement of the freshwater mussel anodonta anatina: a reciprocal transplant experiment between lake and river," Hydrobiologia, vol. 328, no. 1, pp. 49-56, 1996.

[30] W.-Y. Chen, L.-J. Jou, S.-H. Chen, and C.-M. Liao, "A real-time biomonitoring system to detect arsenic toxicity by valve movement in freshwater clam corbicula fluminea," Ecotoxicology, vol. 21, no. 4, pp. 1177-1187, 2012.

[31] L.-J. Jou, S.-C. Lin, B.-C. Chen, W.-Y. Chen, and C.-M. Liao, "Synthesis and measurement of valve activities by an improved online clambased behavioral monitoring system," Computers and electronics in agriculture, vol. 90, pp. 106-118, 2013.

[32] D. Clayton, M. Hills, and A. Pickles, Statistical models in epidemiology. IEA, 1993, vol. 161.

[33] L. Wu, S. Liu, and Y. Yang, "A gray model with a time varying weighted generating operator," Systems, Man, and Cybernetics: Systems, IEEE Transactions on, vol. PP, no. 99, pp. 1-1, 2015.

[34] C. Chambon, A. Legeay, G. Durrieu, P. Gonzalez, P. Ciret, and J. Massabuau, "Influence of the parasite worm polydora sp. on the behaviour of the oyster crassostrea gigas: A study of the respiratory impact and associated oxidative stress," Mar. Biol., vol. 152, pp. 329-338, 2007.

[35] D. Tran, A. Nadau, G. Durrieu, P. Ciret, J. P. Parisot, and J. C Massabuau, "Field chronobiology in molluscan bivalves: How moon and sun cycles interactions deeply drive oyster activity rhythms," Chronobiol. Int., vol. 28, pp. 307-317, 2011.

[36] H. Ahmed, R. Ushirobira, D. Efimov, D. Tran, and J.-C. Massabuau, "Velocity estimation of valve movement in oysters for water quality surveillance," IFAC-PapersOnLine, vol. 48, no. 11, pp. 333-338, 2015.

[37] H. Ahmed, R. Ushirobira, D. Efimov, D. Tran, M. Sow, and J.-C. Massabuau, "Automatic spawning detection in oysters: a fault detection approach," in Control Conference (ECC), 2015 European (to appear), July 2015.

[38] H. Ahmed, R. Ushirobira, D. Efimov, D. Tran, M. Sow, L. Payton, and J.-C. Massabuau, "A fault detection method for automatic detection of spawning in oysters," Control Systems Technology, IEEE Transactions on, vol. PP, no. 99, pp. 1-1, 2015.

[39] Z. T. Zhusubaliyev, A. Medvedev, and M. M. Silva, "Nonlinear dynamics in closed-loop anesthesia: Pharmacokinetic/pharmacodynamic model under pid-feedback," in American Control Conference (ACC), 2014. IEEE, 2014, pp. 5496-5501.

[40] _ - "Bifurcation analysis of pid-controlled neuromuscular blockade in closed-loop anesthesia," Journal of Process Control, vol. 25, pp. 152$163,2015$.

[41] E. Naylor, Chronobiology of marine organisms. Cambridge University Press, 2010.

[42] J. C. Dunlap, J. J. Loros, and P. J. DeCoursey, Chronobiology: biological timekeeping. Sinauer Associates, 2004.

[43] E. Klerman and M. St Hilaire, "On mathematical modeling of circadian rhythms, performance, and alertness," J Biol Rhythms, vol. 22, no. 2, pp. 91-102, 2007.

[44] P. Smolen, D. Baxter, and J. Byrne, "A reduced model clarifies the role of feedback loops and time delays in the drosophila circadian oscillator," Biophysical Journal, vol. 83, pp. 2349-2359, 2002.

[45] A. Goldbeter, "Computational approaches to cellular rhythms," Nature, vol. 420, pp. 238-245, 2002.

[46] H. Ahmed, R. Ushirobira, and D. Efimov, "On robustness of phase resetting to cell division under entrainment," Journal of Theoretical Biology, pp. -, 2015. [Online]. Available: http://www.sciencedirect. com/science/article/pii/S002251931500483X

[47] D. Efimov and A. Fradkov, "Yakubovich's oscillatority of circadian oscillations models," Mathematical Biosciences, vol. 216, pp. 187-191, 2008.

[48] D. Forger and R. Kronauer, "Reconciling mathematical models of biological clocks by averaging on approximate manifolds," SIAM Journal on Applied Mathematics, vol. 62, no. 4, pp. 1281-1296, 2002.

[49] D. Efimov, P. Sacre, and R. Sepulchre, "Controlling the phase of an oscillator: a phase response curve approach," in Proc. IEEE CDC 2009. IEEE, December 2009, pp. 7692-7697.

[50] M. Antle, D. Foley, N. Foley, and R. Silver, "Gates and oscillators: a network model of the brain clock," Journal of Biological Rhythms, vol. 18 , no. 4, pp. 339-350, 2003.

[51] T. Kanamaru, "Van der pol oscillator," Scholarpedia, vol. 2, no. 1, p. 2202, 2007.

[52] D. Efimov, "Phase resetting control based on direct phase response curve," Journal of Mathematical Biology, vol. 63, no. 5, pp. 855-879, 2011.

[53] E. Walter and L. Pronzato, "Identification of parametric models," Communications and Control Engineering, 1997.

[54] O. Nelles, Nonlinear System Identification. Berlin: Springer, 2000.

[55] L. Ljung, System identification. Springer, 1998.

[56] H. T. Siegelmann, B. G. Horne, and C. L. Giles, "Computational capabilities of recurrent narx neural networks," Systems, Man, and Cybernetics, Part B: Cybernetics, IEEE Transactions on, vol. 27, no. 2, pp. 208-215, 1997.

[57] Z. Lu, J. Sun, and K. Butts, "Multiscale asymmetric orthogonal wavelet kernel for linear programming support vector learning and nonlinear dynamic systems identification," Cybernetics, IEEE Transactions on, vol. 44, no. 5, pp. 712-724, 2014

[58] E. Chanthery, L. Trave-Massuyes, and S. Indra, "Fault isolation on request based on decentralized residual generation," Systems, Man, and Cybernetics: Systems, IEEE Transactions on, vol. PP, no. 99, pp. 1-13, 2015.

[59] T. Wang, W. Zhang, C. Ye, J. Wei, H. Zhong, and T. Huang, "Fd4c: Automatic fault diagnosis framework for web applications in cloud computing," Systems, Man, and Cybernetics: Systems, IEEE Transactions on, vol. PP, no. 99, pp. 1-1, 2015

[60] Y. Ren, A. Wang, and H. Wang, "Fault diagnosis and tolerant control for discrete stochastic distribution collaborative control systems," Systems, Man, and Cybernetics: Systems, IEEE Transactions on, vol. 45, no. 3, pp. 462-471, March 2015.

[61] J. Vasu, A. Deb, and S. Mukhopadhyay, "Mvem-based fault diagnosis of automotive engines using dempster - shafer theory and multiple hypotheses testing," Systems, Man, and Cybernetics: Systems, IEEE Transactions on, vol. 45, no. 7, pp. 977-989, July 2015. 


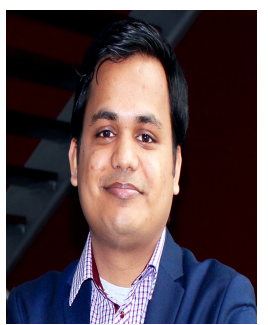

Hafiz Ahmed was born in Dhaka, Bangladesh. He obtained M.Sc. degree in system, control and information technology in 2013 from Joseph Fourier University, Grenoble, France. His M.Sc. thesis was done at the Electric Power Network team of Laboratory of Electrical Engineering and Power Electronics (L2EP), Lille. Since October, 2013 he is a PhD student at the Non-A team of Inria, Lille, France where he works on modelling and estimation of biological rhythms in oysters. His current research interests include modeling, identification, control and stability analysis of dynamical systems with application to environmental monitoring, system biology and renewable energy. He is a student member of IEEE and IEEE control system society.

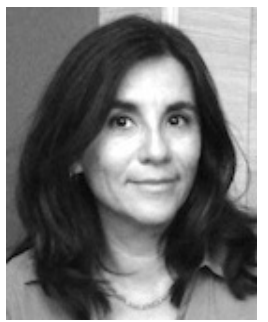

Rosane Ushirobira received her $\mathrm{PhD}$ in Mathematics from the University of Strasbourg (France) in 1996. She was then a post-doctoral fellow at University of Poitiers (France) and at the Technische Universiteit Eindhoven (The Netherlands). Since 1999, she holds an Associate professor position at the University of Bourgogne. In 2010, she defended her Habilitation thesis at Dijon. Her original research field is the Algebraic Lie theory where she has published works on Lie algebras and superalgebras, the Weyl algebra and their representations. In recent years, she became interested in problems in Automatic Control theory. Notably, her work nowadays concerns algebraic methods and applications in this area, especially in parameter estimation problems.

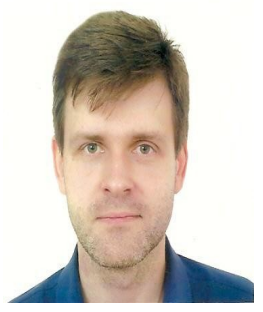

Denis Efimov (SM'11) received the Ph.D. degree in Automatic Control from the Saint-Petersburg State Electrical Engineering University (Russia) in 2001, and the Dr.Sc. degree in Automatic control in 2006 from Institute for Problems of Mechanical Engineering RAS (Saint-Petersburg, Russia). From 2000 to 2009 he was research fellow of the Institute for Problems of Mechanical Engineering RAS, Control of Complex Systems Laboratory. From 2006 to 2011 he was working in the LSS (Supelec, France), the Montefiore Institute (University of Liege, Belgium) and the Automatic control group at IMS lab (University of Bordeaux I, France). Since 2011 he joined the Non-A team at Inria Lille center. He is a member of several IFAC TCs and a Senior member of IEEE. His current research interests include nonlinear oscillation analysis, observation and control, switched and nonlinear system stability.

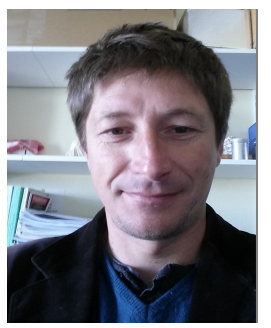

Damien Tran was born in Bergerac, France, in 1972. He got his Ph.D. in aquatic ecotoxicology and ecophysiology from the University of Bordeaux, France in 2001. After several pos-docs, he obtained a permanent position at the CNRS as senior researcher in 2008. Since, he works in the team EA (Aquatic Ecotoxicology) in the laboratory UMR EPOC 5805, University of Bordeaux \& CNRS. His topics of research are focused on aquatic chronobiology and behavior of mollusk bivalves and their disruption by different water contaminations (harmful algae, trace metal, petrol, ...) and the effect of climate change. One of his applications is the development of biosensor called high frequency and noninvasive valvometer, used in situ, to record and monitor valve behavior and its response to environmental changes.

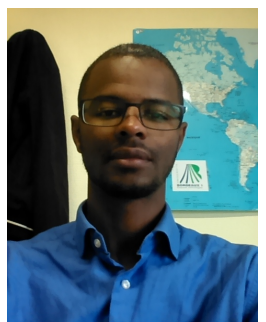

Mohamedou Sow is a research engineer at ADERA, an organism whose members are academics, engineers and entrepreneurs operating in the laboratories of the Aquitaine region. He is mathematician, statistician and member of the EA team at UMR CNRS 5805 EPOC. He studied at the Institute of Mathematics of Bordeaux where he obtained his Master 2 degree before defending, in 2011, his thesis on the development of nonparametric and robust models at the University Bordeaux $1 . \mathrm{He}$ is in charge of the development, the adaptation and the integration to the operational chain of all the codes used in our data production system. He is participating in the management of the material platform, which is the base of our system of production.

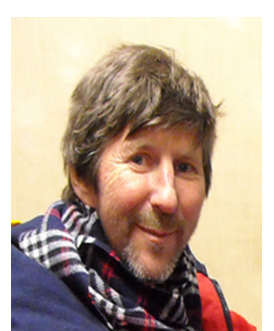

Pierre Ciret is Research Engineer in the CNRS, in the field of electronic applied to biology. He is working at the Marine Biological Station in Arcachon. $\mathrm{He}$ is a member of the team Aquatic Ecotoxicology headed by JC Massabuau (one of the 7 team of the Laboratory EPOC, Environnement et Paléoenvironnements Océaniques et Continentaux, UMR CNRS 5805). He is basically an electronician who has been working on expert system based both on electronics and informatics. He successfully developed numerous machines for the electrophysiology. He has extra competence in sound and image recordings, always at the frontier between biology and electronics

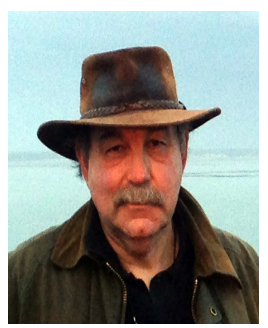

Jean-Charles Massabuau is a research director in the CNRS (Centre National de la Recherche Scientifique, France) and head of the Aquatic Ecotoxicology Team in the UMR CNRS 5805 EPOC, University of Bordeaux and CNRS. Having more than 35 years total research and development experience in the area of comparative respiratory physiology, physiological ecology, ecotoxicology and aquatic systems, his research interests include today the ethology and ecophysiology of bivalve molluscs around the world applied to ecotoxicological problems in the marine environment. Massabuau holds a PhD degree and a State Thesis in animal biology from the University L. Pasteur, Strasbourg, France. Webpages: ResearchGate public page: https://www.researchgate.net/profile/Jean_Charles_Massabuau and http://molluscan-eye.epoc.u-bordeaux 1 .fr/index.php?rubrique=accueil\&lang=en 